\section{Cognitive demons and lental mapses}

\author{
John C. Marshall
}

\section{Absent-Minded? The Psychology \\ of Mental Lapses and Everyday Errors.}

By James Reason and Klara Mycielska. Prentice-Hall: 1982. Pp.262.

Pbk \$6.95, f5.90.

IT IS unreliably reported that the Reverend William A. Spooner after accidently spilling some salt on the tablecloth calmly proceeded to "remove the stain" by pouring a little claret over it. Slips of the tongue, ear, hand and mind are ubiquitous in all our lives and are normally a source of constant delight and amusement - except when, for example, a depressed first of ficer mishears his captain's jovial "cheer up" as "gear up" and promptly retracts the undercarriage while the aircraft is still racing down the runway.

Although Reason and Mycielska do have a chapter on "catastrophic lapses" (from the Charge of the Light Brigade, through the sinking of H.M.S. Victoria, to the Tenerife runway collision) most of their examples are taken from everyday errors whose consequences are no worse than acute embarrassment. One good justification for this concern with seeming trivia is that Reason and Mycielska make out a compelling case that catastrophic errors are simply a subset of "ordinary" errors, "distinguished by circumstantial rather

Journals' review issue 1983

On October 6th Nature will publish the third review supplement devoted to science journals. The two previous supplements (covering journals first published between January 1978 and May 1980, and June 1980 and May 1981) appeared in Nature 293, 341-369 (1981) and 299, 491-514 (1982).

Criteria for inclusion of a journal in the 1983 issue are that:

- the first number appeared, or the journal was re-titled, between June 1981 and May 1982;

- it is published at least three times a year;

- the main language used is English.

Broadly, periodicals of professional interest to scientists will be considered for review, with the exception of abstracts' journals. Journals appearing prior to June 1981 but after January 1978, and not covered in the previous issues, will also be considered.

Publishers and societies are invited to submit four sample issues of journals satisfying the above criteria, including the first and most recent numbers, to the Review Editor, Nature, 4 Little Essex St, London WC2R 3LF, England (London 8366633 ext 2570) as soon as possible. than psychological considerations". The "Freudian slip", where the perpetrator is unconsciously motivated towards disaster, is a very rare beast indeed. Reason and Mycielska therefore argue that accident researchers would do well to consider "the full range of human errors, irrespective of their consequences". Even if this were not so, everyday lapses would still provide invaluable reminders of the complexity of the "automatic pilots" which steer the 99 per cent of our actions we do not (and should not) think about: it is only when we miss the last step that the subtlety of walking down stairs strikes us. And, as the intellectual millipede discovered, 'tis all for the best that most of our activities can be discharged fluently without our paying over much conscious attention to their control.

Reason and Mycielska accordingly distinguish errors of judgement and planning from cases where a satisfactory plan goes awry in execution. On the basis of an extensive questionnaire and diary study, they propose a preliminary taxonomy for the latter cases and establish some basic incidence statistics: "absent-minded" errors occur when habitual tasks that have acquired some degree of automaticity are performed in familiar environments; people seem to differ reliably in their proneness to minor slips and lapses, and this individual liability is not limited to particular domains (memory, action, recognition or language) but rather appears across the board; the occurrence of such errors is associated with distraction and preoccupation but not with obvious emotional or environmental stress, although liability to lapses is correlated with the vulnerability of an individual to stress.

There emerges an overall picture of the mind as a congerie of quasi-autonomous modules ("cognitive demons") whose operation is only intermittently controlled and checked by conscious mental activity. Such control requires focal attention, a strictly limited resource. Automatization of skilled action reduces the frequency with which it is necessary to draw upon attentional resources, at the cost of occasional error as a "demon" is either captured by an environmental variable extraneous to the plan being executed, or is pushed aside by a "demon" of greater intrinsic strength.

Readers familiar with the history of neuropsychology will recognize in this picture John Hughlings Jackson's politicosocial (Evolution and Dissolution of the Nervous System, 1884) and Sigmund Freud's "economic" model of the mind (Project for a Scientific Psychology, 1895). We should now attempt to turn these metaphors into genuine theory with deductive depth and predictive power.

John C. Marshall is in the Neuropsychology Unit, part of the Neuroscience Group at the Radcliffe Infirmary, Oxford.

\section{Nutrition: the great tradition}

\section{John Rivers}

The Elements of the Science of Nutrition.

Reprint of the fourth edition,

first published in 1928.

By Graham Lusk.

Academic: 1983. Pp.844. \$38.50, £26.50.

THERE have been two great periods in the science of nutrition, and Graham Lusk's book reflects both of them. Nutrition began as a physiological science, the nineteenth-century investigation of intermediary metabolism by the only means available, the comparison of input and output. In the early years such studies were both confused and confusing, but as the laws of the conservation of energy became clearly established a body of scientific knowledge was assembled. Developments were shaped by two fortuituous coincidences. Most of the nitrogen in food was in the $\alpha$-amino groups of protein which provided a natural label for studying protein metabolism, while energy exchange, and, to a first approximation, the nature of the nutrients oxidized, could be predicted from respiratory exchange. Thus in the nineteenth century there was a flowering of work on protein and energy metabolism in the whole organism which is associated with such great names as Prout, Pereira, Leibig, Rubner and Voit.

By the end of the century this approach was wearing thin. It must have seemed intellectually bankrupt; a spirit of reductionism was in the air. Claude Bernard captured it when he snarled derisively: "We may of course strike a balance between what a living organism takes in as nourishment and what it gives out in excretion; but the results would be mere statistics incapable of throwing light on the inmost phenomena of nutrition in living beings". The discovery of the vitamins was an early triumph for Bernard's more molecular approach, and in this second golden age can be seen the schism (at once clear and yet difficult to define) between the biochemical and purely nutritional investigations of nutrient metabolism.

Graham Lusk's The Elements of the Science of Nutrition, its title redolent of Euclid's Elements, is a product of the first golden age. It is by no means the end of that great tradition, but it does represent its greatest synthesis. But the book was an anachronism, obsolescent when it first appeared in 1906. This reprint is Lusk's own copy of the most famous fourth edition of 1928 which must have stood like a dinosaur out of its time. The metabolism of protein and of energy take up most of its 850 pages - vitamins are discussed only in onc bricf chapter on the nutritive value of foods which makes up less than five per cent of the book. In this it is the obverse of 